This is the post print version of the article, which has been published in Geografisk Tidsskrift-Danish Journal of Geography 2018, 118 (1), 114-121. http:// dx.doi.org/10.1080/00167223.2017.1405734.

\title{
Developing survey metrics for analysing cross-border proximity
}

\section{Teemu Makkonen ${ }^{1 ; 2 ; *}$ \& Allan M. Williams ${ }^{3}$}

${ }^{1}$ Institute for Advanced Social Research, University of Tampere

Ratapihankatu 55, FI-33014 University of Tampere, Finland

Phone: +358 50509 9133, email: teemu.makkonen@uta.fi

${ }^{2}$ Department of Business and Economics, University of Southern Denmark

Alsion 2, DK-6400 Sønderborg, Denmark

${ }^{3}$ School of Hospitality and Tourism Management, University of Surrey

AP Building, Guildford, Surrey, GU2 7XH, UK

Phone: +44 148368 6308, email: allan.williams@surrey.ac.uk

* Corresponding author 
Abstract: Cross-border innovation cooperation (CBIC) has been heralded as one of the corner stones of innovation-driven growth opportunities for firms located in cross-border regions (CBRs). The success of this cooperation is affected by varying types of proximities identified in the literature as: geographical, institutional, cultural, cognitive, technological, organizational and social. Although the topic has been widely discussed, the validation of the concept of proximity vis-à-vis CBIC has been persistently hindered by a lack of readily available empirical metrics. Therefore, this research note attempts to operationalize the varying types of proximity - in relation to $\mathrm{CBIC}$ - in the form of a questionnaire tested through pilot studies of two CBRs, at the Finnish-Swedish and Danish-German border, and for two contrasting service industries, namely knowledge-intensive business services and tourism. The findings indicate that the developed survey metrics are effective in depicting the phenomenon of proximity. The foundational work undertaken in this research note provides a platform, and catalyst, for more extensive investigations of the topic.

Keywords: Cross-border region; Cross-border cooperation; Innovation; Knowledge intensive business services; Proximity; Tourism 


\section{Introduction}

Cross-border innovation cooperation (CBIC) - defined as cooperation between adjacent areas across borders for innovation - creates competitive advantages for firms located in border regions (OECD, 2013). Firms (the empirical focus of this research note) can cooperate for innovation defined as a process encompassing a wide range of activities such as research and development, organizational changes, training, testing, marketing and design (Lepik \& Krigul, 2014) and the implementation of new or significantly improved product (good or service), process, marketing method, or organizational method in business practices, workplace organization or external relations (OECD, 2005) - purposes across the border, for example, by sharing knowledge and by engaging in joint-product or service development. This can open up opportunities for combining unexploited synergies across the border, laying the foundations for economic growth, by linking knowledge producers from one region with firms capable of applying this knowledge (bringing the product or service into the market) in another one (Muller et al., 2017). Thus, in cross-border settings the potential for innovation can be jointly enhanced, compared to those situations where firms rely solely on intra-regional collaboration. The intensity and outcomes of CBIC are significantly affected by the different types of "proximity" between the adjacent sides of the border (Lundquist \& Trippl, 2013). The proximity types identified in earlier research include geographical distance and similarities/differences in the cognitive, cultural, institutional, organizational, social and technological contexts that firms operate in. Despite the evident importance of the topic, relatively little is known about how to measure the different types of proximity and their outcomes in relation to $\mathrm{CBIC}$ between firms located in border regions.

Moreover, CBRs offer an excellent "laboratory" for analysing proximity in a setting where, despite short geographical distances, the existence of a national border between the actors usually render them dissimilar in many other dimensions of proximity (e.g. in terms of institutional proximity), thereby providing an interesting case for the proximity literature. To the best of the authors' knowledge, no study to date has investigated all the different proximity types with primary data in a regional cross-border context. Instead, earlier studies on proximity and CBIC, have either discussed the issue conceptually (Lundquist \& Trippl, 2013; Makkonen \& Rohde, 2016; Trippl, 2010; Weidenfeld, 2013), concentrated on a limited set of proximity types (Coenen, Moodysson, \& Asheim, 2004; Hansen, 2013; Makkonen, 2015; Weidenfeld, Björk, \& Williams, 2016) or measured them with secondary statistical data (Makkonen, Weidenfeld, \& Williams, 2016): they have not 
utilised a questionnaire that would allow researchers to study the topic with more targeted primary data that can be statistically analysed. The literature on CBIC, thus, still suffers from a lack of empirical metrics to validate the importance of proximity in cross-border settings (Makkonen \& Rohde, 2016; Makkonen et al., 2016). The aim of this research note therefore is to fill this gap by introducing novel survey metrics suitable for analysing cross-border proximity vis-á-vis CBIC. The feasibility of the suggested metrics is tested via pilot studies of two CBRs, the Finnish-Swedish Tornio River Valley (TRV) and Danish-German Sønderjylland-Schleswig (SjS), and two distinct service industry sectors, namely knowledge-intensive business services (KIBS) and tourism.

\section{Cross-border proximity and how to measure it with questionnaire items}

Drawing from the literature on cross-border regional innovation systems, this research note introduces survey metrics to analyse the roles of various intertwined types of proximity as enablers of and/or barriers to CBIC (Hansen, 2013; Lundquist \& Trippl, 2013; Makkonen \& Rohde, 2016; Makkonen et al., 2016; Trippl, 2010; Weidenfeld, 2013). Here, the different types of proximity (Table 1) were operationalized with questionnaire items on a seven point Likert-scale (Appendix 1). This made it possible to differentiate empirically between the closely intertwined types of proximity as follows:

1. Geographical proximity: The existing evidence (Biggiero \& Sammarra, 2010) indicates that geographical proximity matters for innovation-related knowledge exchanges. However, simple Euclidean distances are less important for $\mathrm{CBIC}$ than are the time-cost dimensions of proximity i.e. the ease of crossing borders in terms of travel times, travel costs and border formalities/customs and restrictions (Knoben \& Oerlemans, 2006; Lundquist \& Trippl, 2013; Rast \& Kroll, 2006).

Despite its importance, geographical proximity is not the only type of proximity that is relevant for CBIC: various types of relational (i.e. non-spatial) proximity have also been identified. The definitions that describe these different types of relational proximity tend to overlap and have been grouped and categorized in various ways in the existing literature. Here we have followed the reasoning of Knoben and Oerlemans (2006) and grouped them into the following sets:

2. Institutional and cultural proximity: Although sometimes referred to as separate types of proximity (Lagendijk \& Lorentzen, 2007), a more common approach has been to link these together, since the concepts of institutional and cultural proximity are strongly inter-related 
and, as such, are challenging to disentangle (Boschma, 2005; Knoben \& Oerlemans, 2006; Zeller, 2004): this is because institutions are largely determined by culture (Hofstede, 2001). Previous studies (Koschatzky, 2000) have shown that cultural proximity, commonly discussed against the backdrop of institutions (such as a shared language or common laws), is important for successful CBIC (i.e. for the cooperation to accomplish the desired aim or result). Thus, common formal and informal institutions facilitate cooperation (Boschma, 2005). Formal institutions hindering CBIC have been defined in the existing literature as relating to large differences in laws and regulations and low levels of support from local administrative organizations and business associations (Knoben \& Oerlemans, 2006; Torre \& Gilly, 2000). In contrast, proximity in informal institutions includes such intertwined issues as similarities/differences in language, business culture, and norms and values (Boschma, 2005; Hansen, 2014; Lundquist \& Trippl, 2013).

3. Cognitive and technological proximity: At first, cognitive proximity might seem similar to the concept of technological proximity, but there is also a difference between these two constructs: "cognitive proximity refers to the extent to which actors can communicate efficiently, whereas technological proximity refers to the extent to which actors can actually learn from each other" (Knoben \& Oerlemans, 2006, p. 78). Thus, these closely related proximity types refer to shared ways of thinking and shared educational backgrounds (cognitive proximity), similar technical/technological (ICT, software, etc.) requirements, know-how and expertise (technological proximity) (Heringa, Horlings, van der Zouwen, van den Besselaar, \& van Vierssen, 2014; Lundquist \& Trippl, 2013; Moodysson \& Jonsson, 2007). Distance in terms of, for example, a lack of shared knowledge bases and areas of expertise are detrimental, whereas proximity in these dimensions is beneficial to CBIC (Makkonen et al., 2016).

4. Organizational and social proximity: Organizational and social proximity have been commonly linked together in the existing literature because they share key similarities (Knoben \& Oerlemans, 2006). However, a distinction between them can be made: "social proximity refers to personal aspects of collaboration (such as trust and networking), whereas organizational proximity focuses on similarities and differences in the organizational context" (Heringa et al., 2014, p. 691). Proximities in both dimensions facilitate cooperation (Boschma, 2005; Hansen, 2014; Knoben \& Oerlemans, 2006): the way in which practices in organizations are informed by common conventions, that is the similarity of organizational 
contexts or organizational proximity, and personal (long-standing) relationships and trust (social proximity) have been shown to affect cooperation practices positively in cross-border contexts (Labrianidis \& Vogiatzis, 2011; Makkonen, 2015).

Table 1. Operationalization of proximity types through questionnaire items.

\section{Geographical proximity}

a) Travel times (Knoben \& Oerlemans, 2006)

b) Travel costs (Lundquist \& Trippl, 2013)

c) Border formalities/customs and restrictions (Rast \& Kroll, 2006)

\section{Institutional and cultural proximity}

Formal institutions
a) Laws and regulations (Knoben \& Oerlemans, 2006)
b) Local public authorities (Torre \& Gilly, 2000)
c) Local business associations (Torre \& Gilly, 2000)
Informal institutions
d) Language (Lundquist \& Trippl, 2013)
e) Business culture (Hansen, 2014)
f) Norms and values (Boschma, 2005)

\section{Technological and cognitive proximity}

a) Technical know-how (Lundquist \& Trippl, 2013)

b) Technological requirements; e.g. instruments, software (Heringa et al., 2014)

c) Educational backgrounds (Moodysson \& Jonsson, 2007)

Organizational and social proximity

a) Organizational contexts and practices (Knoben \& Oerlemans, 2006)

b) Trust (Hansen, 2014)

c) Social networking (Boschma, 2005)

If the distances in terms of these varying types of proximity between regions on the adjacent sides of the border are substantial, the border acts as a barrier to innovation cooperation. Contrarily, if the distances are not an issue, and instead there are certain levels of similarity between the regions, then knowledge can flow more freely across the border, thereby facilitating CBIC (Lundquist \& Trippl, 2013). However, too much proximity might also constitute a barrier to CBIC: little knowledge will flow between regions if they are too similar, i.e. if they have nothing to learn from each other (Trippl, 2010). 


\section{Empirical issues}

\section{Tornio River Valley and Sønderjylland-Schleswig}

A CBR can be defined as an area consisting of "adjacent territories... whose economic and social life is directly and significantly affected by proximity to an international boundary" (Weidenfeld, 2013, p. 192) or as "a bounded territorial unit composed of the territories of authorities participating in a CBC (cross-border cooperation) initiative" (Perkmann, 2003, p. 157). Here the latter definition was applied and the boundaries of the case study CBRs were "drawn" based on official delineations of CBC initiatives. Historically, TRV (Figure 1) was a united territory: it was the Finnish war (1808-1809) between Sweden and the Russian empire, after which Finland became an autonomous region of the Russian Empire, which made the TRV a CBR. It consists of the town of Tornio and the municipalities of Ylitornio, Pello, Kolari, Muonio and Enontekiö from the Finnish side, and the municipalities of Haparanda, Övertorneo and Pajala (in some definitions also Gällivare) and the town of Kiruna from the Swedish side (www.tornedalen.org). When Finland proclaimed independence in 1917, the TRV was transformed into the present-day Finnish-Swedish CBR. The Swedish side of the CBR has remained ethnically mixed with a significant Finnish-speaking minority, partly due to in-migration from Finland, which has resulted in a certain cultural coherence between the two regions. Nevertheless, collaboration amongst the actors in the TRV, despite substantial EU-funding for developing cooperation in the CBR, for example, in tourism, exhibits a strong national orientation (Prokkola, 2008). 


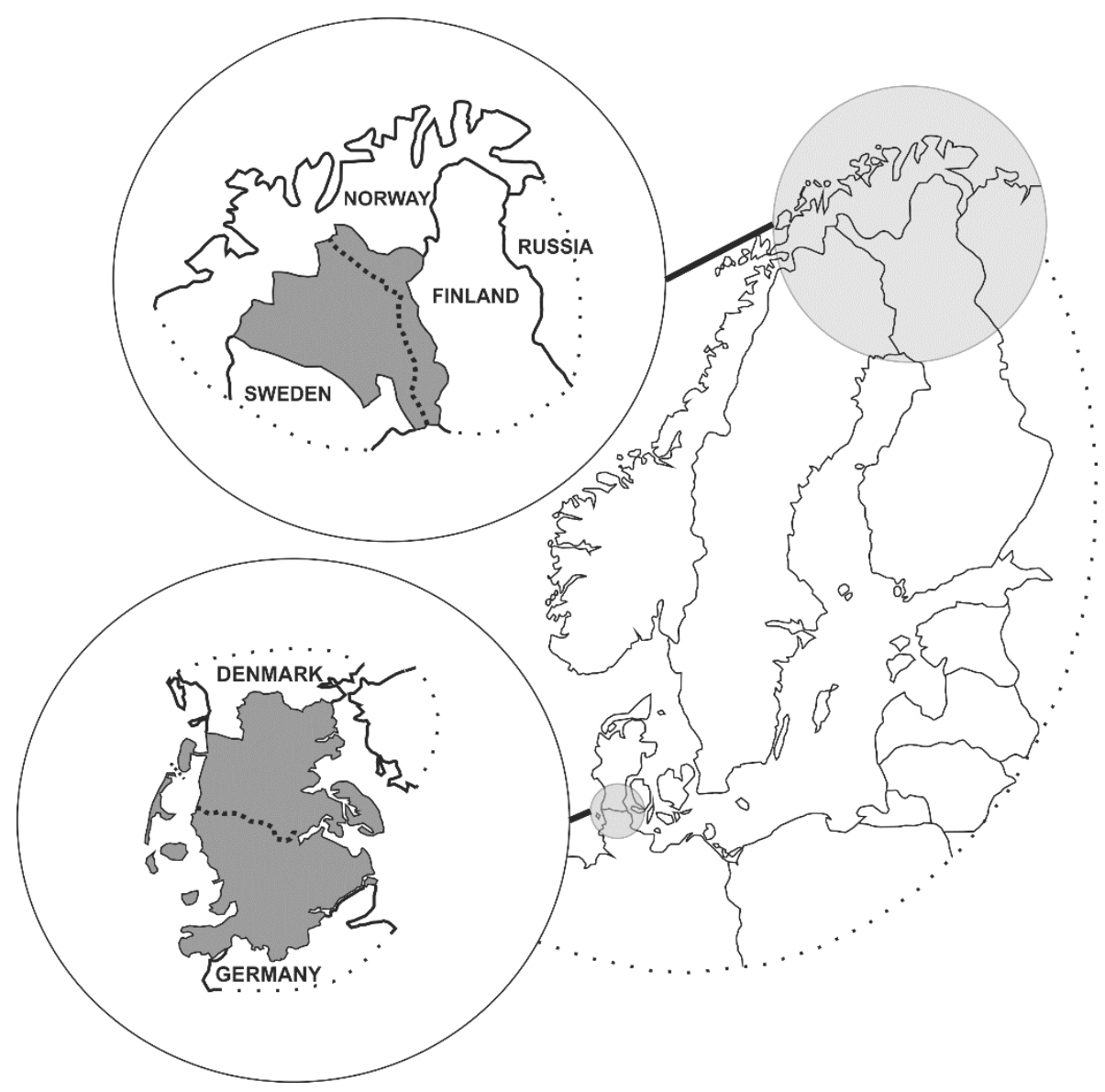

Figure 1. Tornio River Valley and Sønderjylland-Schleswig (highlighted in grey).

SjS consists of the municipalities of Aabenraa, Haderslev, Sønderborg and Tønder from the Danish side, and the districts of Schleswig-Flensburg and Nordfriesland and the urban district of Flensburg from the German side (www.region.dk). It has also been a unified territory in the past. A dispute over the control of the region led to the Schleswig wars in the 1800's, and eventually in 1864 , the dominion over the region shifted from Denmark to Germany. However, the northern parts of the region - where the majority of the population were ethnic Danes - were reunified with Denmark, following a referendum in 1920. This "gave birth" to the present-day border and to the Danish- and German-speaking minorities living on opposing sides of that border (Figure 1). Despite the existence of these minorities, the economies of the opposing border regions have remained largely separate with few tangible (measurable) forms of cooperation (Makkonen, 2015), even though this has been promoted by considerable support from EU-funded cross-border programmes (Klatt \& Herrmann, 2011) 
The two CBRs were selected for the pilot study because of their similarities. Most specifically, these criteria are: 1) the presence of significant cross-border language minorities 2) "ample" EU-funding for developing cooperation, but 3) (apparently) low levels of actual cross-border interaction (Klatt \& Herrmann, 2011; Makkonen, 2015; Prokkola, 2008). The aim was, thus, to find two similar CBRs to examine whether or not the results are similar. If the results are similar in the two CBRs, as is expected, this indicates that the questionnaire items have been understood in a similar way and the items have (face) validity.

\section{Knowledge-intensive business services and tourism}

KIBS and tourism have rarely been discussed together in the literature on innovation cooperation (Borodako, Berbeka, \& Rudnicki, 2015; Roberts, 2006). Although tourism and KIBS share some generic similarities as service industries, there are also sharp differences between these sectors. KIBS - as a high-tech service industry - have been identified as one of the defining elements of innovation-oriented regions (Corrocher \& Cusmano, 2014). In contrast, the tourism sector - as a low-tech industry - has often been assumed to be largely an imitator (applying innovations produced in other sectors) rather than truly innovating in its own right (Hjalager, 2015). The comparison of these different service sectors provides methodological insights into CBIC in both low- and high-tech sectors, thereby responding to the research gap identified by Harrington and Daniels (2006) who stressed the need for sector- and location-specific studies to disentangle the familiar generalizations concerning cooperation relationships in the service industries. We adhered to the list of KIBS-related NACE classes provided by Muller and Doloreux (2009) and the classifications of tourist-related sectors by MacFeely, Delaney, and O'Donoghue (2013) and Ooi, Hooy, and Som (2015) to delineate our sample of firms.

\section{Pilot study}

The survey was targeted at firms in two different service industry sectors, namely KIBS and tourism (based on NACE classes), and two CBRs, namely TRV and SjS. The contact details of the firms were acquired from web marketing companies - which source the data by phone, via trade associations and from the Internet (big data technologies) - resulting in a comprehensive list of local businesses. However, the list included a large share of generic email addresses (e.g. info@hotelsonderborg.dk). This is reflected in the modest number of responses: 60 usable responses were received (Table 2). 
However, for the purposes of a pilot study, the reasonable price of purchasing email contact details, and the ease of executing online surveys, outweigh the limitations of the number of responses.

Table 2. The pilot study sample.

\begin{tabular}{lcccc}
\hline & \multicolumn{3}{c}{ Industry } & Total \\
& KIBS & Tourism & Unknown \\
\hline Tornio River Valley & 11 & 15 & 2 & $\mathbf{2 8}$ \\
Sonderjylland-Schleswig & 18 & 12 & 2 & $\mathbf{3 2}$ \\
Total & $\mathbf{2 9}$ & $\mathbf{2 7}$ & $\mathbf{4}$ & $\mathbf{6 0}$ \\
\hline
\end{tabular}

\section{Findings}

"Proximity scores" were calculated, based on the individual questionnaire items described in Appendix 1, in order to depict the level of proximity between the adjacent sides of the CBRs. Firstly, all the proximity related questionnaire items were calculated as averages: Proximity $=\frac{1}{n} \sum_{i=1}^{n} Q I_{i}$, where $Q l_{i}$ refers to an individual questionnaire item and $n$ to the number of questionnaire items included. Secondly, similar measures were calculated for the individual proximity categories included in the questionnaire: geographical, formal institutions, informal institutions, technological and cognitive and organizational and social. The higher this proximity score, the greater the significance of an individual proximity type as a barrier to CBIC.

The pilot study results indicate that the different proximity types correlate strongly with each other. This is not surprising considering their overlapping definitions and conceptual interdependencies. However, there were also statistically significant differences, when measured with the Wilcoxon signed rank test, between the different proximity types: respondents considered that differences in formal and informal institutions constitute the most significant barriers to $\mathrm{CBIC}$ in the surveyed CBRs and for the surveyed service sectors (Table 3). The internal consistency of the proposed survey measures can be considered fairly good, as evidenced by the high Cronbach's alpha score $(\alpha=0.869)$ for our proximity measure. This indicates that the different questionnaire items measure the same phenomenon, namely proximity. Additionally, principal component analyses showed that the items loaded on a single principal component: all questionnaire items had loadings over 0.3 for the first principal component. This provides further evidence of the reliability of the survey metrics for 
measuring proximity. There were no statistically significant differences in the proximity measures across the two CBRs, nor in the two sectors surveyed (Figure 2).

Table 3. Descriptive statistics (Spearman's rho and Wilcoxon signed rank test) on the different proximity types.

\begin{tabular}{|c|c|c|c|c|c|c|}
\hline Proximity types & Tests & Geographical & $\begin{array}{l}\text { Institutional } \\
\text { (formal) }\end{array}$ & $\begin{array}{c}\text { Institutional } \\
\text { (informal) }\end{array}$ & $\begin{array}{c}\text { Technological/ } \\
\text { Educational }\end{array}$ & $\begin{array}{c}\text { Organizational/ } \\
\text { Social }\end{array}$ \\
\hline $\begin{array}{l}\text { Institutional } \\
\text { (formal) }\end{array}$ & $\begin{array}{l}\text { Correlation } \\
\text { Wilcoxon (p) }\end{array}$ & $\begin{array}{c}0.547^{* *} \\
<0.001^{* *}\end{array}$ & & & & \\
\hline $\begin{array}{l}\text { Institutional } \\
\text { (informal) }\end{array}$ & $\begin{array}{l}\text { Correlation } \\
\text { Wilcoxon (p) }\end{array}$ & $\begin{array}{c}0.504^{* *} \\
<0.001^{* *}\end{array}$ & $\begin{array}{c}0.375^{* *} \\
0.516\end{array}$ & & & \\
\hline $\begin{array}{l}\text { Technological/ } \\
\text { Educational }\end{array}$ & $\begin{array}{l}\text { Correlation } \\
\text { Wilcoxon (p) }\end{array}$ & $\begin{array}{l}0.279 \\
0.884\end{array}$ & $\begin{array}{c}0.337^{*} \\
<0.001^{* *}\end{array}$ & $\begin{array}{l}0.393 * * \\
0.001 * *\end{array}$ & & \\
\hline $\begin{array}{l}\text { Organizational/ } \\
\text { Social }\end{array}$ & $\begin{array}{l}\text { Correlation } \\
\text { Wilcoxon (p) }\end{array}$ & $\begin{array}{c}0.605^{* *} \\
0.024 *\end{array}$ & $\begin{array}{l}0.509 * * \\
0.008 * *\end{array}$ & $\begin{array}{c}0.489 * * \\
0.012 *\end{array}$ & $\begin{array}{c}0.677^{* *} \\
0.064\end{array}$ & \\
\hline & Mean & 2.00 & 3.01 & 2.83 & 2.05 & 2.40 \\
\hline
\end{tabular}

** Significant at the 0.01 level

* Significant at the 0.05 level

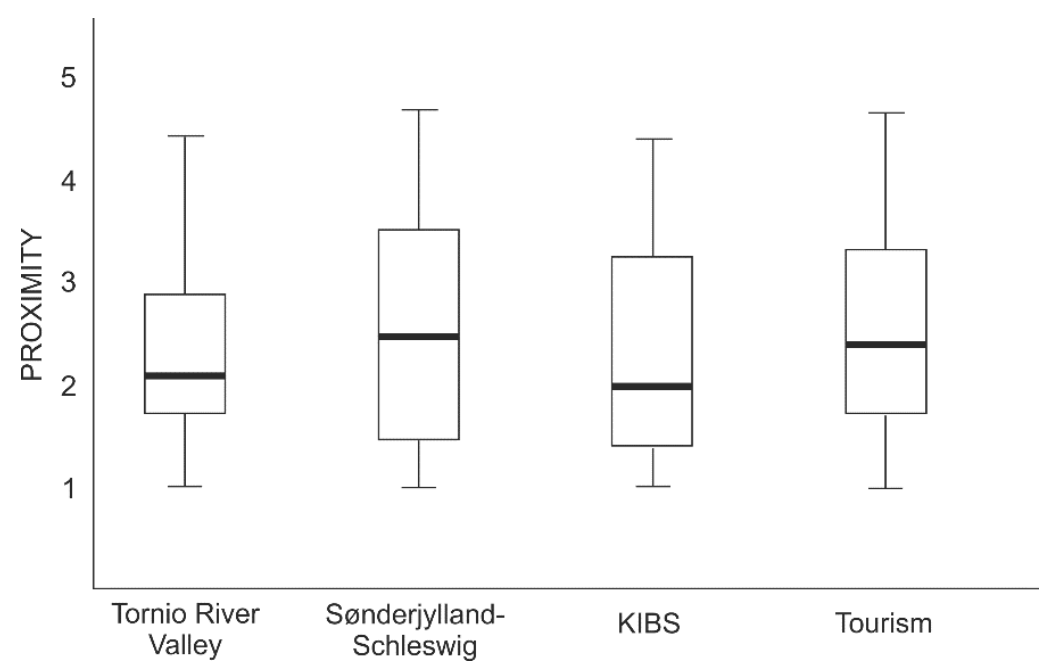

Figure 2. The perceived impact of border for cross-border innovation cooperation in the four sub-samples of the pilot study as indicated by the proximity score (higher scores mean a stronger negative impact).

To summarize, the findings from the pilot studies support the feasibility and reliability of the operationalization of proximity through survey metrics. Firstly, it was possible to pinpoint similarities between the surveyed CBRs. Therefore, the proposed survey metrics seem to function in a similar fashion in different geographical settings. Secondly, the statistically tested internal consistency of the proposed metrics indicate reliability: in other words, the metrics measure the same phenomenon, proximity. Thirdly, however, the research did identify interesting statistically 
significant differences between the various proximity types, highlighting the importance of the lack of both formal and informal institutional proximity as a barrier to CBIC.

The pilot study aspects of this research note do of course impose limitations on the interpretation of these findings. However, the results showing the importance of institutional proximity are in line with earlier literature on CBIC (Koschatzky, 2000), and with the related literature, for example, on non-local university-industry collaboration (Hong \& Su, 2013). The similarity between the two CBRs was, as expected, based on their similarly low interest in cooperating across the border as reported in the earlier literature (Klatt \& Herrmann, 2011; Makkonen, 2015; Prokkola, 2008). In contrast, more surprising was the similarity between the investigated sectors. Since earlier studies (Harrington \& Daniels, 2006) suggest that there should be differences between them, we expected that the different proximity types would constitute different barriers in each case. However, this was not supported by our results, which might very well be due to our small sample size. Therefore, the results need to be critically evaluated and contrasted in future studies employing larger datasets.

\section{Concluding remarks}

Despite the evident importance of proximity in facilitating successful processes CBIC, relatively little is known about how to measure the different types of proximity in cross-border settings. Therefore, the aim of this research note was to introduce questionnaire metrics for measuring cross-border proximity and its impacts on CBIC. The individual survey items depicting the varying types of proximity (geographical, institutional and cultural, cognitive and technological as well as organizational and social) were operationalized via studying a range of related proximity literatures. The results of the pilot study indicate that the proposed questionnaire metrics function reasonably well in depicting the varying proximity types. The developed and tested questionnaire metrics for depicting cross-border proximity in relation to CBIC can be applied in a wide range of other studies. It can, thus, potentially help decision-makers to identify the aspects which most seem to hamper $\mathrm{CBIC}$ in their CBR: these are issues to be dealt with (via policies, support, funding, training, etc.) in order to intensify CBIC.

For example, in the pilot study locations firms identified informal institutional hindrances as the most significant barriers for CBIC. These barriers can be tackled via improvements in continuing 
education and training (courses on language skills, cultural sensitiveness, doing business in the neighbouring country, etc.) (Beck, 2008), which applies also to cognitive and technological differences (Figure 3). In the case of formal institutions, the means to alleviate the barriers are commonly out-of-reach for local decision-makers. Therefore, local governments should aim to lobby national governments (and the EU within Europe) to standardize or harmonise laws and regulations. However, if the barriers in formal institutions are, in fact, due to low levels of interest amongst local actors for supporting CBIC, the change has to begin within themselves. Infrastructure projects (e.g. $\varnothing$ resund Bridge) can improve the situation in cases where travel times and costs constitute a major barrier (Hansen, 2013). If the barriers stem from social differences, local governments need to facilitate interaction amongst individuals from different sides of the border: familiarity builds trust, and trust is a necessity for successful cross-border networking and CBIC (Kaisto \& Nartova, 2008).

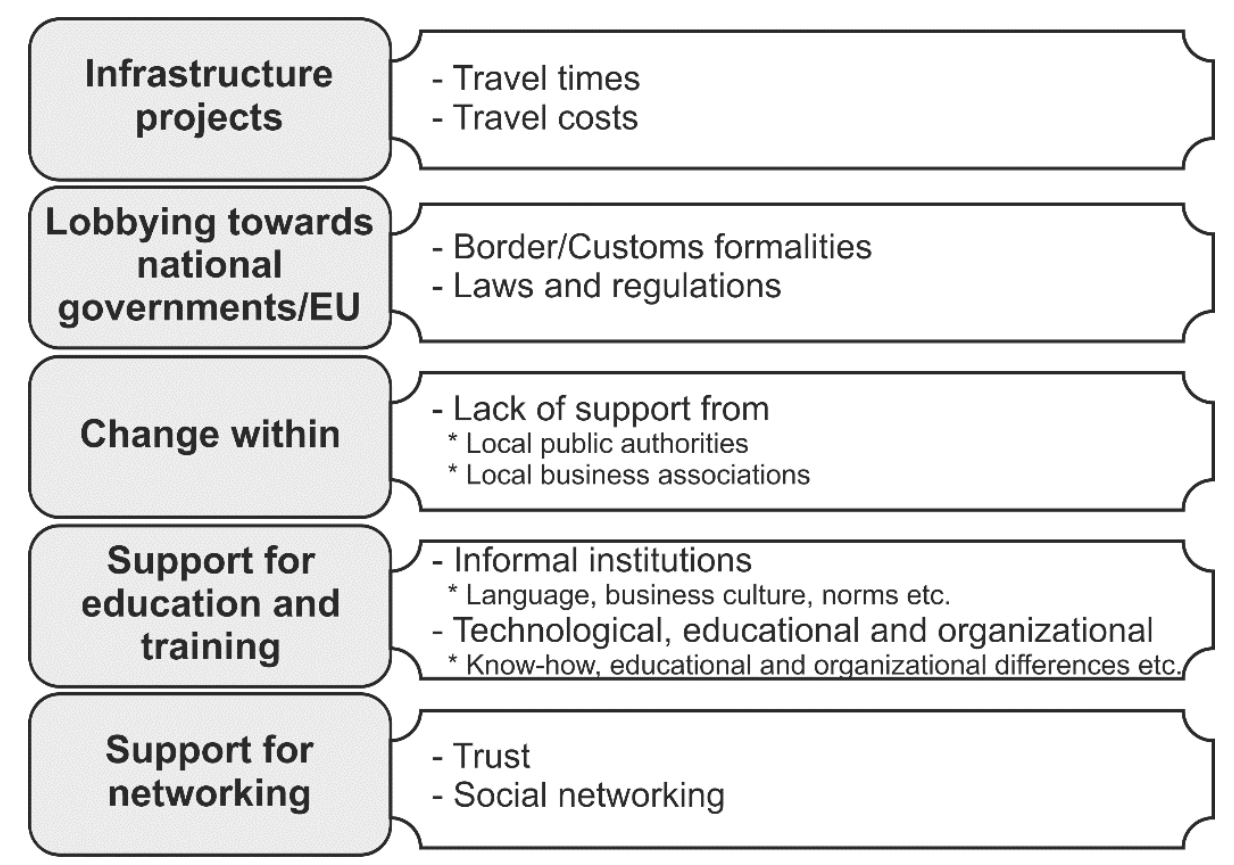

Figure 3. Policy options (left) for facilitating cross-border innovation cooperation in the presence of different types of barriers (right).

The aim of this research note was to function as a platform - and hopefully as a catalyst - for more intensive studies of proximity and CBIC. Therefore, an evident direction for further studies includes the widening of the sample and the inclusion of more nuanced innovation and cooperation related questions in the questionnaire, which would allow the utilization of more sophisticated statistical methods and more precise estimates of how the varying proximity types affect CBIC. There is also a need to disentangle whether the answers given are based on actual experiences of CBIC or rather 
on stereotypes. The scope should also be widened to other CBRs and industry sectors, since it is likely that the result may vary, for example, if applied to the external borders of the EU and to other industries.

\section{Acknowledgements}

We are grateful to the survey respondents for their time and effort, to the anonymous reviewers for their helpful comments and to Charlotte Lund Hansen, Rannveig Edda Hjaltadóttir and Timo Mitze from the University of Southern Denmark, Stephan Rohde from the University of Flensburg and Mats Stjernberg from the University of Helsinki for their help in translating our questionnaire into Danish, German and Swedish.

\section{Funding}

This work was supported by the Marie Curie Actions (Intra-European Fellowship for career development) within the Seventh Framework Programme (FP7) of the EU under Grant PIEF-GA-2013-624930.

\section{References}

Beck, J. (2008). Lessons from an institute for cross-border cooperation on the Franco-German border. Journal of CrossBorder Studies in Ireland, 9, 38-49.

Biggiero, L., \& Sammarra, A. (2010). Does geographical proximity enhance knowledge exchange? International Journal of Technology Transfer and Commercialisation, 9, 283-305.

Borodako, K., Berbeka, J., \& Rudnicki, M. (2015). Tourism enterprises as buyers of knowledge-intensive business services. SAGE Open, 5, 1-10.

Boschma, R. (2005). Proximity and innovation. Regional Studies, 39, 61-74.

Coenen, L., Moodysson, J., \& Asheim, B. (2004). Nodes, networks and proximities. European Planning Studies, 12, 10031018.

Corrocher, N., \& Cusmano, L. (2014). The 'KIBS engine' of regional innovation systems. Regional Studies, 48, 1212-1226.

Hansen, T. (2013). Bridging regional innovation: Cross-border collaboration in the Øresund Region. Geografisk Tidsskrift, $113,25-38$.

Hansen, T. (2014). Juggling with proximity and distance. Economic Geography, 90, 375-402.

Harrington, J., \& Daniels, P. (2006). International and regional dynamics of knowledge-based services. In J. Harrington \& P. Daniels (Eds.), Knowledge-based services, internationalization and regional development (pp. 1-12). Aldershot: Ashgate.

Heringa, P., Horlings, E., van der Zouwen, M., van den Besselaar, P., \& van Vierssen, W. (2014). How do dimensions of proximity relate to the outcomes of collaboration? Economics of Innovation and New Technology, 23, 689-716.

Hjalager, A-M. (2015). 100 innovations that transformed tourism. Journal of Travel Research, 54, 3-21.

Hofstede, G. (2001). Culture's consequences. Thousand Oaks: Sage. 
Hong, W., \& Su, Y. (2013). The effect of institutional proximity in non-local university-industry collaborations. Research Policy, 42, 454-464.

Kaisto, B., \& Nartova, N. (2008). Imatra-Svetogorsk kaksoiskaupunki: Asennebarometri [Imatra-Svetogorsk twin city: Attitude barometer]. Lappeenranta: Etelä-Karjala Instituutti.

Klatt, M., \& Herrmann, H. (2011). Half empty or half full? Over 30 years of regional cross-border cooperation within the EU. Journal of Borderlands Studies, 26, 65-87.

Knoben, J., \& Oerlemans, L. (2006). Proximity and inter-organizational collaboration. International Journal of Management Reviews, 8, 71-89.

Koschatzky, K. (2000). A river is a river: Cross-border networking between Baden and Alsace. European Planning Studies, 8, 429-449.

Labrianidis, L., \& Vogiatzis, N. (2011). Local delocalization across borders. Journal of Borderlands Studies, $26,35-51$.

Lagendijk, A., \& Lorentzen, A. (2007). Proximity, knowledge and innovation in peripheral regions. European Planning Studies, 15, 457-466.

Lepik, K., \& Krigul, M. (2014). Challenges in knowledge sharing for innovation in cross-border context. International Journal of Knowledge-Based Development, 5, 332-343.

Lundquist, K-J., \& Trippl, M. (2013). Distance, proximity and types of cross-border innovation systems. Regional Studies, 47, 450-460.

MacFeely, S., Delaney, J., \& O'Donoghue, F. (2013). Using business registers to conduct a regional analysis of enterprise demography and employment in the tourism industries. Tourism Economics, 19, 1293-1316.

Makkonen, T. (2015). Scientific collaboration in the Danish-German border region of Southern Jutland-Schleswig. Geografisk Tidsskrift, 115, 27-38.

Makkonen, T., \& Rohde, S. (2016). Cross-border regional innovation systems: Conceptual backgrounds, empirical evidence and policy implications. European Planning Studies, 24, 1623-1642.

Makkonen, T., Weidenfeld, A., \& Williams, A. (2016). Cross-border regional innovation system integration. Tijdschrift voor Economische en Sociale Geografie. doi:10.1111/tesg.12223

Moodysson, J., \& Jonsson, O. (2007). Knowledge collaboration and proximity. European Urban and Regional Studies, 14, 115-131.

Muller, E., \& Doloreux, D. (2009). What we should know about knowledge-intensive business services. Technology in Society, 31, 64-72.

Muller, E., Zenker, A., Hufnagl, M., Héraud, J-A., Schnabl, E., Makkonen T., \& Kroll, H. (2017). Smart specialisation strategies and cross-border integration of regional innovation systems. Environment and Planning C, 35, 684702.

OECD (2005). Oslo Manual (3rd ed.). Paris: OECD Publishing.

OECD (2013). Regions and innovation: Collaborating across borders. Paris: OECD Publishing.

Ooi, C-A., Hooy, C-W., \& Som, A. (2015). Diversity in human and social capital: Empirical evidence from Asian tourism firms' corporate board composition. Tourism Management, 48, 139-153.

Perkmann, M. (2003). Cross-border regions in Europe. European Urban and Regional Studies, 10, $153-171$.

Prokkola, E-K. (2008). Resources and barriers in tourism development. Fennia, 186, 31-46. 
Rast, C., \& Kroll, S. (2006). Incoming tourism. In H. Wachowiak (Ed.), Tourism and borders (pp. 47-76). Aldershot: Ashgate.

Roberts, J. (2006). Internationalization of management consultancy services. In J. Harrington \& P. Daniels (Eds.), Knowledge-based services, internationalization and regional development (pp. 101-124). Aldershot: Ashgate.

Torre, A., \& Gilly, J-P. (2000). On the analytical dimension of proximity dynamics. Regional Studies, 34, 169-180.

Trippl, M. (2010). Developing cross-border regional innovation systems. Tijdschrift voor Economische en Sociale Geografie, 101, 150-160.

Weidenfeld, A. (2013). Tourism and cross border regional innovation systems. Annals of Tourism Research, 42, $191-213$.

Weidenfeld, A., Björk, P., \& Williams, A. (2016). Cognitive and cultural proximity between service managers and customers in cross-border regions. Scandinavian Journal of Hospitality and Tourism, 16, S66-S86.

Zeller, C. (2004). North Atlantic innovative relations of Swiss pharmaceuticals and the proximities with regional biotech arenas. Economic Geography, 80, 83-111.

\section{Appendix 1: The questionnaire: proximity-related questions}

Please indicate the extent to which you agree with the following statements about whether the border is a barrier to innovation cooperation with firms or institutions from the other side of the border:

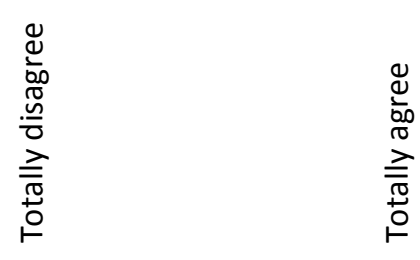

\section{Geographical proximity}

a) Travel times are too long $\quad 1 \quad 2 \quad 3 \quad 4 \quad 5 \quad 6 \quad 7$

b) Travel costs are too high

c) Border formalities/customs and restrictions constitute a problem

$\begin{array}{lllllll}1 & 2 & 3 & 4 & 5 & 6 & 7\end{array}$

Institutional and cultural differences

\section{Formal institutions}

$\begin{array}{lllllll}1 & 2 & 3 & 4 & 5 & 6 & 7\end{array}$

d) Laws and regulations are too different

e) Local public authorities are not supportive towards cross-border cooperation

f) Local business associations (e.g. Chambers of Commerce) are not supportive towards cross-border cooperation

\section{Informal institutions}

g) Language differences constitute a problem

h) Business cultures are too different

i) Norms, values and habits are too different

Technological and educational differences

j) Technical know-how is too different

k) Technological requirements; e.g. instruments or software are too different

I) Educational backgrounds are too different Organizational and social differences

m) Organizational contexts and ways of doing things are too different

n) Trust issues constitute a problem

$\begin{array}{lllllll}1 & 2 & 3 & 4 & 5 & 6 & 7\end{array}$

$\begin{array}{lllllll}1 & 2 & 3 & 4 & 5 & 6 & 7\end{array}$

$\begin{array}{lllllll}1 & 2 & 3 & 4 & 5 & 6 & 7\end{array}$

o) The role and ways of social networking are too different $\begin{array}{lllllll}1 & 2 & 3 & 4 & 5 & 6 & 7\end{array}$

$\begin{array}{lllllll}1 & 2 & 3 & 4 & 5 & 6 & 7\end{array}$

$\begin{array}{lllllll}1 & 2 & 3 & 4 & 5 & 6 & 7\end{array}$

$\begin{array}{lllllll}1 & 2 & 3 & 4 & 5 & 6 & 7\end{array}$

$\begin{array}{lllllll}1 & 2 & 3 & 4 & 5 & 6 & 7\end{array}$

$\begin{array}{lllllll}1 & 2 & 3 & 4 & 5 & 6 & 7\end{array}$

$\begin{array}{lllllll}1 & 2 & 3 & 4 & 5 & 6 & 7\end{array}$

$\begin{array}{lllllll}1 & 2 & 3 & 4 & 5 & 6 & 7\end{array}$

$\begin{array}{lllllll}1 & 2 & 3 & 4 & 5 & 6 & 7\end{array}$ 